\title{
Significant prevalence of NR3C1 mutations in incidentally discovered bilateral adrenal hyperplasia: results of the French MUTA-GR Study
}

\author{
Géraldine Vitellius ${ }^{1,2}$, Séverine Trabado ${ }^{1,3}$, Christine Hoeffel', Jérôme Bouligand ${ }^{1,3}$, Antoine Bennet ${ }^{5}$, \\ Frederic Castinetti ${ }^{6}$, Bénédicte Decoudier ${ }^{2}$, Anne Guiochon-Mantel ${ }^{1,3}$, Marc Lombes ${ }^{1,7, *}$ and Brigitte Delemer ${ }^{2, *}$ \\ on behalf of investigators of the MUTA-GR Study ${ }^{\dagger}$
}

1IINSERM UMR_S U1185, Fac Med Paris Sud, Université Paris Sud, Université Paris-Saclay, Le Kremlin Bicêtre, France, ²Service d'EndocrinologieDiabète-Nutrition, Hôpital Robert Debré, CHU Reims, Reims, France, ${ }^{3}$ Service de Génétique Moléculaire, Pharmacogénétique et Hormonologie, Hôpitaux Universitaires Paris Sud, AH-HP, CHU Bicêtre, Le Kremlin Bicêtre, France, ${ }^{4}$ Service de Radiologie, Hôpital Robert Debré, CRESTIC, CHU Reims-URCA, Reims, France, ${ }^{5}$ Service d'Endocrinologie, Maladies Métaboliques et Nutrition, $\mathrm{CHU}$ Toulouse, Toulouse, France, ${ }^{6}$ Service d'Endocrinologie, CHU de la Timone, Marseille, France, and ${ }^{7}$ Service d'Endocrinologie et des Maladies de la Reproduction, Hôpitaux Universitaires Paris Sud, AH-HP, CHU Bicêtre, Le Kremlin Bicêtre, France

Correspondence should be addressed to $\mathrm{M}$ Lombès or $\mathrm{B}$ Delemer Email

marc.lombes@u-psud.fr or bdelemer@chu-reims.fr

\begin{abstract}
Background: Recently discovered mutations of $N R 3 C 1$ gene, encoding for the GR, in patients with glucocorticoid resistance and bilateral adrenal incidentalomas prompted us to investigate whether GR mutations might be associated with adrenal hyperplasia.

Objective: The multicenter French Clinical Research Program (Muta-GR) was set up to determine the prevalence of GR mutations and polymorphisms in patients harboring bilateral adrenal incidentalomas associated with hypertension and/or biological hypercortisolism without clinical Cushing's signs.

Results: One hundred patients were included in whom NR3C1 sequencing revealed five original heterozygous GR mutations that impaired GR signaling in vitro. Mutated patients presented with mild glucocorticoid resistance defined as elevated urinary free cortisol ( $1.7 \pm 0.7$ vs $0.9 \pm 0.8$ upper limit of normal range, $P=0.006)$, incomplete $1 \mathrm{mg}$ dexamethasone suppression test without suppressed 8-AM adrenocorticotrophin levels $(30.9 \pm 31.2 \mathrm{vs} 16.2 \pm 17.5 \mathrm{pg} /$ $\mathrm{mL}$ ) compared to the non-mutated patients. Potassium and aldosterone levels were lower in mutated patients $(3.6 \pm 0.2$ vs $4.1 \pm 0.5 \mathrm{mmol} / \mathrm{L}, P=0.01$, and $17.3 \pm 9.9$ vs $98.6 \pm 115.4 \mathrm{pg} / \mathrm{mL}, P=0.0011$, respectively) without elevated renin levels, consistent with pseudohypermineralocorticism. Ex vivo characterization of mutated patients' fibroblasts demonstrated GR haploinsufficiency as revealed by below-normal glucocorticoid induction of FKBP5 gene expression. There was no association between GR polymorphisms and adrenal hyperplasia in this cohort, except an over-
\end{abstract} representation of $B c / l$ polymorphism.

Conclusion: The $5 \%$ prevalence of heterozygous NR3C1 mutations discovered in our series is higher than initially thought and encourages GR mutation screening in patients with adrenal incidentalomas to unambiguously differentiate from Cushing's states and to optimize personalized follow-up.

\section{Introduction}

Glucocorticoids are fundamental hormones that regulate various biological functions involved in development, metabolism, inflammatory processes and stress. Their

www.eje-online.org

https://doi.org/10.1530/EJE-17-1071 (c) 2018 European Society of Endocrinology Printed in Great Britain actions are mediated by the glucocorticoid receptor (GR), an intracellular receptor protein that functions as ligand-activated transcription factor (1). Human GR 
(hGR), encoded by the NR3C1 gene (MIM\#138040), located in the chromosome 5, comprises 10 exons. Alternative splicing of the hGR gene in exon 9 generates two homologous receptor isoforms: $\alpha$ and $\beta$ (2). Exon 2 encodes for the N-terminal domain and exons 3 and 4 encode for the DNA-binding domain (DBD). Exons 5-9 encode for the ligand-binding domain (LBD). NR3C1 loss-of-function mutations have been associated with a glucocorticoid resistance syndrome (MIM\#615962). Moreover, among many NR3C1 polymorphisms described to date, some were associated with increased (N363S, $B c l I)$ or decreased (ER22/23EK) glucocorticoid sensitivity, adrenal incidentalomas (ER22/23EK, BclI, 9 $\beta$ ), obesity and metabolic syndrome (N363S, BclI, 9 $\beta)(3,4)$.

Twenty-four loss-of-function germinal mutations in NR3C1 have been reported and shown to impair intracellular GR signaling $(5,6,7,8,9,10,11,12,13,14$, 15). Fifty percent of mutated probands presented with hypertension, frequently associated with hypokalemia, while the majority of mutated women presented with hirsutism. GR mutation carriers had elevated or normal adrenocorticotrophin (ACTH) levels associated with high urinary free cortisol (UFC) and lacked negative glucocorticoid feedback loop on the hypothalamicpituitary adrenal (HPA) axis.

We recently discovered the first nonsense heterozygous mutation of human NR3C1 (MIM \#615962), R469X, in a context of bilateral adrenal hyperplasia incidentally discovered (16). The proband displayed no Cushing's syndrome signs but had high blood pressure with hypokalemia. Hormonal evaluations revealed a biological hypercortisolism with normal ACTH level. Functional characterization demonstrated GR haploinsufficiency. Moreover, in mouse models, Michailidou and coworkers (17) had shown that heterozygous $\mathrm{GR}^{+/-}$exhibited bilateral adrenal hyperplasia but normal plasma ACTH levels. Taken together, these data led us to hypothesize that impairment in GR signaling could be related to adrenocortical hyperproliferation and/or hyperplasia.

Bilateral adrenal incidentalomas represent 15-20\% of adrenal incidentalomas $(18,19,20)$. This prevalence drastically increases with aging. The best known causes of bilateral adrenal masses are related to macronodular adrenal hyperplasia, potentially regulated by aberrant $G$ proteincoupled receptors (21), familial pheochromocytoma, primary hyperaldosteronism (22), ARMC5 gene mutation $(23,24), 21$-hydroxylase deficiency, multiple endocrine neoplasia type 1 (MEN-1), infectious diseases, nonfunctioning tumor or metastatic diseases (18). However, a direct relationship between adrenal incidentalomas and altered GR signaling has never been investigated thus far nor evoked in recent published guidelines $(25,26)$.

In the present study, we hypothesized that GR mutations might represent a novel genetic cause of adrenocortical proliferation in the context of autonomous glucocorticoid secretion. A French National, Hospital Clinical Research Program (PHRC), Muta-GR, was set up to determine the prevalence of NR3C1 mutations in a cohort of patients presenting with bilateral adrenal incidentalomas combined with high blood pressure (HBP) and/or biological hypercortisolism without Cushingoid features. The second aim was at evaluating common GR polymorphisms frequency in our series associated with adrenal hyperplasia compared to the general population. We discovered five novel heterozygous NR3C1 mutations, among which three have been already functionally characterized $(16,27)$. All reported mutations impaired GR signaling either by glucocorticoid or DNA-binding defects leading to a clear-cut GR haploinsufficiency. The relatively high prevalence of NR3C1 mutations in our cohort emphasizes the importance of GR genetic screening in selected patients enabling their appropriate management and to optimize their follow-up strategies.

\section{Patients and methods}

\section{Study protocol}

The study referred to as Muta-GR (ClinicalTrials.gov Identifier: NCT02810496) is a multicenter and transversal PHRC study. The primary objective of this study was to evaluate the prevalence of NR3C1 mutations in patients with bilateral adrenal incidentalomas. To refine the rate of GR genetic alterations, patients with hypertension and/or biological hypercortisolism without Cushing's syndrome signs were selected. Inclusion criteria were the presence of incidentally discovered bilateral adrenal hyperplasia in patients with no overt signs of Cushing's syndrome. Adrenal imaging was performed in patients for unrelated reasons. Adrenal hyperplasia was radiologically characterized and defined using morphological and volumetric criteria. To date, objective characteristics of adrenal hyperplasia are only poorly specified. In the present study, adrenal hyperplasia was defined according to three main criteria: adrenal limb (medial and lateral) $>5 \mathrm{~mm}$ (28), adrenal volume above reference values in the general population (as referred in Carsin et al. (29)) or the presence of adrenal nodule $>10 \mathrm{~mm}$. The presence of hypertension was defined as a systolic blood pressure (SBP) $>140 \mathrm{~mm} \mathrm{Hg}$, diastolic blood pressure (DBP) $\geq 90 \mathrm{mmHg}$ 
and/or patients under any current antihypertensive therapy. Hypercortisolism was assessed based on either high UFC (above reference values or upper limit of normal range (ULN)), midnight serum cortisol $>50 \mathrm{nmol} / \mathrm{L}$ (30) or serum 8 -AM cortisol $>50 \mathrm{nmol} / \mathrm{L}$ after $1 \mathrm{mg}$ dexamethasone (DXM) suppression test (1 mg DST). Nine patients had UFC above ULN, 23 had cortisol $>50 \mathrm{nmol} / \mathrm{L}$ after $1 \mathrm{mg}$ DST while 58 had midnight serum cortisol $>50 \mathrm{nmol} / \mathrm{L}$. Cushing's syndrome signs were evaluated by clinician endocrinologists (thin skin, hirsutism, easy bruising, faciotruncal adiposity and amyotrophy). We excluded patients with clinical Cushing's syndrome, current cancer, age under 18 years or without written patients' consent.

The study protocol conformed to the ethics guidelines in accordance with the Declaration of Helsinki and was approved by the Comité de Protection des Personnes, CPP Est III on Aug 12, 2011.

\section{Patients}

One hundred twenty-seven patients were enrolled between Aug 2012 and Oct 2016 in twenty endocrinology departments of French University Hospitals (see the list of investigators).

All investigators filled out forms listing sex, birth date, weight $(\mathrm{kg})$, height $(\mathrm{cm})$, SBP, DBP $(\mathrm{mmHg})$ and cardiac disease (existence of heart failure or coronaropathy), dyslipidemia, current antihypertensive, anti-diabetic or anti-cholesterol medications. Body mass index (BMI) was calculated as weight in kilograms divided by the square of height in meters.

Biochemical and hormonal analyses were collected from each center: kalemia, creatininemia, creatiniuria, fasting glycaemia (8-AM), glycated hemoglobin (HbA1c), total cholesterol $(\mathrm{g} / \mathrm{L})$, HDL cholesterol $(\mathrm{g} / \mathrm{L})$, LDL cholesterol (g/L), UFC, 8-AM and midnight plasma cortisol, cortisol after $1 \mathrm{mg}$ DST, 8-AM ACTH level, plasma aldosterone and renin concentrations in supine position.

\section{Imaging study}

Multidetector row computed tomography (MDCT) examinations were performed in each different institution (see the list of investigators). Protocols for the acquisition of images covering the abdomen were variable in terms of intravenous administration of iodinated contrast agent and also in terms of scanning parameters, but they always included thin slices covering the abdomen. Anonymized MDCT data were transferred to a dedicated workstation equipped with Myrian 64 Expert VL1.15.0 software (Intrasense, Montpellier, France). The maximum width of the gland (defined as the maximum width perpendicular to the long axis of the body gland, at the junction of adrenal limbs and the body) and width of the adrenal limbs (defined as the maximum thickness of the medial and lateral limbs of the gland perpendicular to the long axis of the limb) were measured as previously described by Vincent $e t$ al. (31). The presence of adrenal nodules $>10 \mathrm{~mm}$, their precise size, attenuation when recordable and degree of enhancement were noted. Nodules suspicious for nonadenomas were excluded from the study, on the basis of the consensual criteria for the diagnosis of adenoma. Adrenal gland volume was calculated according to Carsin-Vu (29), on the same workstation. The adrenal contour used for volume calculation was traced semiautomatically for all patients by one investigator, after an intense training session with an expert radiologist. The software then automatically calculated adrenal volume by summing the area on each slice. Care was taken to exclude adjacent fat. Total adrenal volume (TAV) was determined as the sum of the right and left adrenal volume measurements and expressed in $\mathrm{cm}^{3}$.

\section{DNA analysis}

Each blood sample was sent to University Hospital of Kremlin Bicêtre. Genomic DNA was extracted from white blood cells. The entire coding regions of the hGR $\alpha$ and the hGR $\beta$ were amplified and sequenced by Sanger method with primers previously described (16). We also examined some GR SNPs: rs6189, rs6190, rs10482622, rs6195, rs41423247, rs6188 and rs6196.

\section{Fibroblast culture}

After skin biopsy, primary cultures of patients' fibroblasts were grown at $37^{\circ} \mathrm{C}$ with $5 \% \mathrm{CO}_{2}$ in DMEM High Glucose ( $4.5 \mathrm{~g} / \mathrm{L})$ (Life Technology), $2 \mathrm{mM}$ glutamine, $2 \mathrm{mM}$ Hepes (GIBCO), $1 \mathrm{mM}$ sodium pyruvate (GIBCO), $100 \mathrm{U} / \mathrm{mL}$ penicillin, $100 \mu \mathrm{g} / \mathrm{mL}$ streptomycin (GE Healthcare) and 15\% fetal bovine serum (Biowest, Nuaillé, France).

\section{RT-real-time qPCR}

Patients' fibroblasts were washed once with ice-cold PBS. Total RNA was extracted with the TRI-reagent (Molecular Research Center, Inc., Euromedex, Mundolsheim, France), according to the manufacturer's recommendations. Total 
RNA extraction, reverse transcription and real-time qPCR were performed essentially as previously described (32). cDNA samples were amplified by real-time qPCR by using the QuantStudio6 Flex System (Life Technologies). All samples were quantified in duplicate. Relative expression in a given sample was normalized to the internal reference rRNA $18 \mathrm{~S}$ values, where the control condition values are arbitrarily set at $100 \%$. Results are expressed as means \pm S.E.M.

\section{Primer design for RT-qPCR assays}

Primer pairs encompassing the targeted regions were designed by using NCBI's software Primer BLAST. Primers were provided from Eurogentec (www.eurogentec.com), purified by the selective precipitation optimized process (SePOP), desalted and delivered at $100 \mu \mathrm{M}$ concentration in water. Primer sequences were as follows: h18S Forward: GTG CAT GGC CGT TCT TAG TTG, Reverse: TGA ATG CCA CAT CTC TGC AGT; hFKBP5 Forward: CCG GAG AAC CAA ACG GAA A, Reverse: TGA ATG CCA CAT CTC TGC AGT.

\section{Statistical analysis}

Results are expressed as means \pm S.D. in tables and means \pm s.e.M. in figures. Statistical analyses were performed with Prism 5 software (GraphPad Software). Comparison of continuous variables among different groups was performed using Mann-Whitney $U$ tests or Fisher $t$ tests for categorical variables. $P$ values of less than 0.05 were considered significant.

\section{Results}

\section{Clinical, radiological and biochemical characteristics of eligible patients}

One hundred and twenty-seven patients were initially enrolled. Eighteen patients were excluded after analysis of the MDCT by the radiologist because the abnormalities in terms of size and/or volume of the gland or of the presence of a macronodule were not bilateral. Nine patients were also excluded since they had neither hypertension nor biological hypercortisolism. One hundred patients were finally included in this study. Genetic analysis revealed five original heterozygous NR3C1 mutations (see flow chart in Fig. 1).

Characteristics of all included patients are reported in Table 1. Among eligible patients, mean age was
$64.2 \pm 9.2$ years with a sex ratio close to 1 . More than eighty-seven percent of these patients had hypertension, most of them (79\%) had an antihypertensive therapy. Patients had a high BMI $\left(29.8 \pm 6.2 \mathrm{~kg} / \mathrm{m}^{2}\right)$. Thirtyfour percent of the patients presented with diabetes. Twenty-two percent of the patients exhibited cardiac diseases (heart failure, coronary deficiency, coronary artery disease). Total cholesterol was in the normal range with normal HDL cholesterol and LDL cholesterol levels. Thirty-four patients had elevated UFC above ULN, while 40 patients had plasma cortisol levels $>50 \mathrm{nmol} / \mathrm{L}$ after $1 \mathrm{mg}$ DST. Fourteen patients had both abnormalities while among them, 9 patients had also normal or high ACTH levels and 5 patients had low ACTH levels $(<10 \mathrm{pg} / \mathrm{mL})$, suggesting biological autonomous hypercortisolism.

All patients had bilateral hyperplastic adrenal glands with high average volumes of right and left adrenals, measured at 10.2 and $13.4 \mathrm{~cm}^{3}$, respectively. Hyperplasia was due to either lateral or medial limb $>5 \mathrm{~mm}$ or adrenal adenomas $>10 \mathrm{~mm}$ (Fig. 2) or right or left adrenocortical volumes above normal range (Table 1). Forty eight percent of patients had right adrenal hyperplasia while $75 \%$ had left adrenal hyperplasia, 71\% had right nodular adrenal and $81 \%$ had left nodular adrenal.

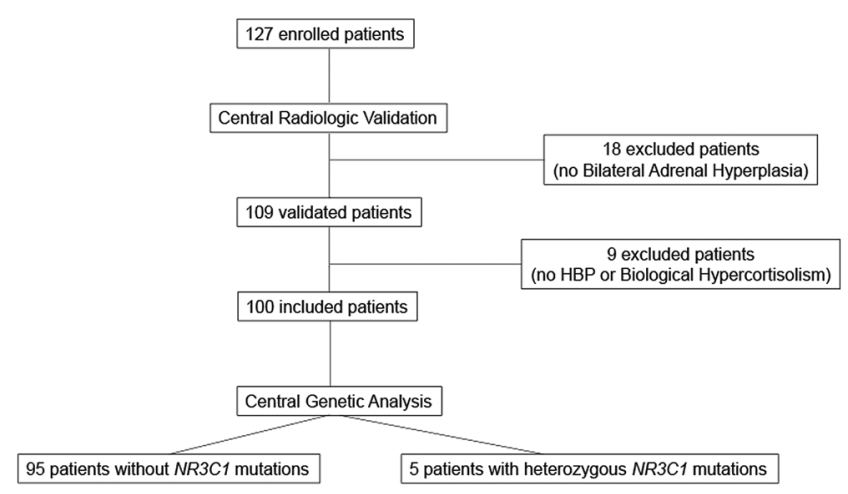

\section{Figure 1}

Flow chart of the study design. 127 patients were initially enrolled. After standardized examination of MDCT by an expert radiologist (CHU Reims), 18 patients were excluded because they had no bilateral adrenal incidentalomas. Nine patients had no clinical or biological inclusion criteria: neither hypertension (HBP) nor biological hypercortisolism. One hundred patients were finally included in the Muta-GR study. Centralized genetic analysis (CHU Bicêtre) identified 5 original heterozygous NR3C1 mutations. HBP, high blood pressure; NR3C1 gene encoding for the human glucocorticoid receptor (GR). 
Table 1 Basal characteristics of 100 included patients.

\begin{tabular}{|c|c|c|c|}
\hline & $\boldsymbol{n}$ (data) & All patients & Normal range \\
\hline \multicolumn{4}{|l|}{ Clinical } \\
\hline Age (years) & 100 & $64.2 \pm 9.2$ & \\
\hline Sex $M / W$ & 100 & $52(52.0 \%) / 48(48.0 \%)$ & \\
\hline Hypertension & 100 & $87(87.0 \%)$ & \\
\hline Antihypertensive treatment & 100 & $79(79.0 \%)$ & \\
\hline BMI $\left(\mathrm{kg} / \mathrm{m}^{2}\right)$ & 98 & $29.8 \pm 6.2$ & $<25$ \\
\hline Waist circumference $(\mathrm{cm})$ : men & 15 & $104.7 \pm 13.7$ & $<94$ \\
\hline Waist circumference $(\mathrm{cm})$ : women & 15 & $100.7 \pm 19.6$ & $<80$ \\
\hline Diabetes & 100 & $34(34.0 \%)$ & \\
\hline Cardiac disease & 100 & $22(22.0 \%)$ & \\
\hline \multicolumn{4}{|l|}{ Biological } \\
\hline Kalemia (mmol/L) & 95 & $4.1 \pm 0.5$ & $3.5-5$ \\
\hline Fasting glycaemia (mmol/L) & 82 & $6.2 \pm 2.1$ & $<7.8$ \\
\hline $\mathrm{HbA} 1 \mathrm{c}(\%)$ & 68 & $6.5 \pm 1.2$ & $<6.5$ \\
\hline Total cholesterol (g/L) & 89 & $1.9 \pm 0.4$ & $<2$ \\
\hline HDL cholesterol (g/L) & 86 & $0.5 \pm 0.2$ & $>0.45$ \\
\hline LDL cholesterol (g/L) & 85 & $1.1 \pm 0.4$ & $<1$ \\
\hline \multicolumn{4}{|l|}{ Hormonology } \\
\hline $\operatorname{UFC}(>\mathrm{N})$ & 93 & $0.9 \pm 0.8 \mathrm{~N}$ & $<1$ \\
\hline 8-AM cortisol (nmol/L) & 94 & $448 \pm 218$ & $248-635$ \\
\hline Midnight cortisol (nmol/L) & 64 & $160 \pm 145$ & $<50$ \\
\hline 8-AM АCTH $(\mathrm{pg} / \mathrm{mL})$ & 91 & $17.0 \pm 18.6$ & $10-50$ \\
\hline Cortisol after $1 \mathrm{mg}$ DXM test (nmol/L) & 65 & $104 \pm 126$ & $<50$ \\
\hline \multicolumn{4}{|l|}{ Radiology } \\
\hline Right adrenal volume $\left(\mathrm{cm}^{3}\right)$ & 96 & $10.2 \pm 5.7$ & $2.5-5.1$ \\
\hline Left adrenal volume $\left(\mathrm{cm}^{3}\right)$ & 94 & $13.4 \pm 6.7$ & $2.9-6.1$ \\
\hline Total adrenal volume $\left(\mathrm{cm}^{3}\right)$ & 94 & $23.6 \pm 10.5$ & $5.7-11.1$ \\
\hline Right adrenal hyperplasia & 100 & $48(48.0 \%)$ & \\
\hline Left adrenal hyperplasia & 100 & $78(75.7 \%)$ & \\
\hline Bilateral hyperplasia & 100 & $48(48.0 \%)$ & \\
\hline Bilateral nodular & 100 & $21(21 \%)$ & \\
\hline Left hyperplasia and right nodular & 100 & $20(20.0 \%)$ & \\
\hline Left hyperplasia and elevated right adrenal volume & 100 & $26(26.0 \%)$ & \\
\hline Right nodule $>10 \mathrm{~mm}$ & 100 & $71(71 \%)$ & \\
\hline Left nodule $>10 \mathrm{~mm}$ & 100 & $81(81 \%)$ & \\
\hline
\end{tabular}

Clinical, biochemical, hormonal, radiological features of the 100 included patients. $\mathrm{BMI}$, body mass index; DST, dexamethasone suppression test; HbA1C, glycated hemoglobin; HDL, high density level; LDL, low density level; M/W, men/ women; UFC, 24-h urinary free cortisol; ULN, upper limit of normal range.

\section{Five heterozygous NR3C1 mutations}

Five original heterozygous NR3C1 mutations were discovered in our series. As illustrated in Fig. 3, three patients harbored heterozygous missense mutations:
R477S (arginine (R) to serine (S) substitution at aminoacid position 477) located in the exon 4 encoding for the DBD, Q501H (glutamine (Q) to histidine (H) substitution at amino-acid position 501 in the exon 5) and L672P

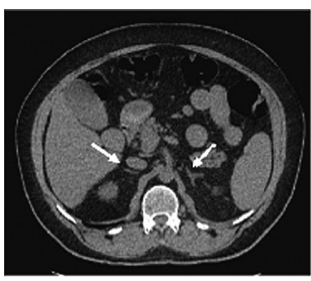

Normal adrenal glands

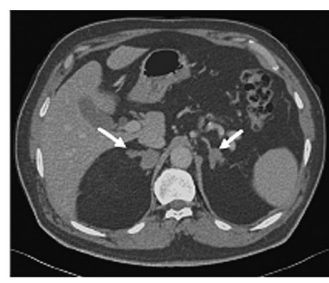

Bilateral adrenal hyperplasia

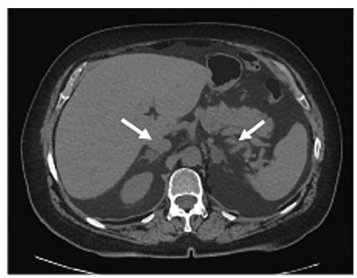

Thin bilateral nodular adrenal

\section{Figure 2}

Radiological examples of adrenal bilateral hyperplasia. MDCT examinations. Left panel: normal adrenal glands. Bilateral adrenal hyperplasia (middle panel) and thin adrenal limb with bilateral macroadenoma (right panel) are presented. White arrows indicate the position of adrenal glands. 


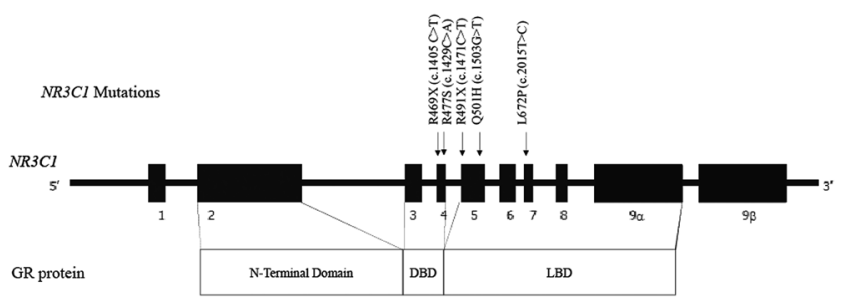

Figure 3

NR3C1 mutations identified. Localization of the 5 heterozygous GR mutations on the NR3C1 gene with schematic representation of the exon composition. Two mutations are located in the DBD, R469X (arginine (R) to stop (X) substitution at amino-acid position 469), R477S (arginine

(R) to serine (S) substitution at amino-acid position 477 ) and 3 mutations are located in the ligand-binding domain (LBD), R491X (arginine (R) to stop (X) substitution at amino-acid position 491), Q501H (glutamine (Q) to histidine $(\mathrm{H})$ substitution at amino-acid position 501), L672P (leucine (L) to proline (P) substitution at amino-acid position 672 ).

(leucine (L) to proline $(\mathrm{P})$ substitution at amino-acid position 672 in the exon 7) located in the LBD. Two patients carried heterozygous nonsense mutations: R469X (arginine (R) to stop (X) substitution at aminoacid position 469 in the exon 4) located in the DBD and R491X (arginine (R) to stop (X) substitution at aminoacid position 491 in the exon 5), located in the LBD. Functional in vitro characterization of R469X, R477S and L672P have already been reported and revealed impairment in GR signaling for all GR mutants $(16,27)$. Collectively, this indicates a global prevalence of GR mutations of 5\% among 100 included patients.

The clinical, biological, hormonal and radiological characteristics of these mutated patients were compared to those of non-mutated patients (Table 2). Mutated patients were younger $(53.2 \pm 7.7$ years old, means \pm S.D., $P=0.007)$, but only 2 mutated patients out of five (40\%) had hypertension compared to $89.5 \%$ of the non-mutated patients $(P=0.02)$. The percentage of cardiovascular events was not different between non-mutated and mutated patients, likewise for cardiac risk factors (diabetic features, BMI and LDL cholesterol), except for HDL cholesterol, slightly higher $(0.70 \pm 0.27 \mathrm{~g} / \mathrm{L})$ in mutated patients compared to non-mutated patients $(0.51 \pm 0.17 \mathrm{~g} / \mathrm{L}, P=0.03)$. As expected, higher UFC was found in mutated patients compared to the non-mutated patients $(1.7 \pm 0.7$ vs $0.9 \pm 0.8$ ULN, $P=0.006$, respectively) without suppressed 8-AM ACTH levels $(30.9 \pm 31.2 \mathrm{pg} /$ $\mathrm{mL}$ in mutated patients vs $16.2 \pm 17.5 \mathrm{pg} / \mathrm{mL}$ ), associated with more elevated cortisol after $1 \mathrm{mg}$ DST $(227.4 \pm 174$ vs $93.4 \pm 117.4 \mathrm{nmol} / \mathrm{L}, P=0.035)$. There was no difference for midnight plasma cortisol between mutated and non-mutated patients. Among the 5 mutated patients, 4 patients had an increased UFC, normal or high ACTH levels and elevated cortisol after $1 \mathrm{mg}$ DST, consistent with glucocorticoid resistance syndrome.

Potassiumlevelswerelowerin mutated patientscompared to non-mutated patients $(3.6 \pm 0.2$ vs $4.1 \pm 0.5 \mathrm{mmol} / \mathrm{L}$, $P=0.01)$. Interestingly, aldosterone levels were statistically lower in mutated patients $(17.3 \pm 9.9$ vs $98.6 \pm 115.4 \mathrm{pg} / \mathrm{mL}$ in non-mutated patients, $P=0.0011)$. Renin levels were low or normal in all mutated patients except for the patient harboring R477S mutation due to angiotensin-converting enzyme (ACE) inhibitor treatment. Therefore, low plasma renin and aldosterone levels, associated with kalemia $<4 \mathrm{mmol} / \mathrm{L}$ are recurrent biological features prevailing in mutated patients of the Muta-GR cohort.

Adrenocortical morphology of mutated patients (number of nodules, adrenal hyperplasia, TAV) was not different from non-mutated patients. One patient had bilateral adrenal hyperplasia (patient with R469X mutation), one had thin bilateral nodular adrenals (patient with L672P mutation) and others had either nodular thin or right/left adrenal hyperplasia.

\section{GR haploinsufficiency in mutated patients}

We obtained fibroblasts from skin biopsies of four mutated patients (patients carrying GR R469X, R477S, R491X, Q501H mutations, since patient with GR L672P mutation was lost of follow-up). We confirmed by sequencing that these skin fibroblasts carried both normal and mutated GR alleles and thus presumably endogenously expressed both wild-type and mutated GR, notwithstanding the possibility of nonsense mediated RNA decay, previously demonstrated for GR stop mutation (16). We next evaluated directly the DXM induction of a well-known glucocorticoid-induced target gene FKBP5 in fibroblasts' patients (Fig. 4).

After 6-h DXM exposure, expression levels of FKBP5 mRNA were significantly lower in all mutated fibroblasts $\left(\mathrm{GR}^{\mathrm{WT} / \mathrm{mut}}\right)$ compared to non-mutated fibroblasts $\left(\mathrm{GR}^{\mathrm{WT} /}\right.$ WT (control): 50\% for GR ${ }^{\mathrm{WT} / \mathrm{R} 469 \mathrm{X}}$ (R469X) $(P<0.01), 22.7 \%$ for $\mathrm{GR}^{\mathrm{WT} / \mathrm{R} 4775}$ (R477S) $(P=0.0018), 31.3 \%$ for $\mathrm{GR}^{\mathrm{WT} /}$ R491X (R491X) $(P=0.0101), 1.3 \%$ for $\mathrm{GR}^{\mathrm{WT} / \mathrm{Q} 501 \mathrm{H}}(\mathrm{Q} 501 \mathrm{H})$ $(P=0.0022))$. These findings provide direct support for a GR haploinsufficiency, driven by heterozygous NR3C1 mutations, consistent with glucocorticoid resistance observed in the mutated patients. 


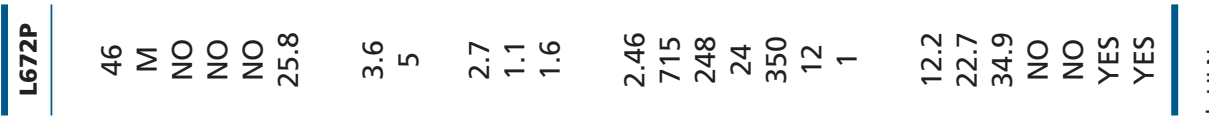

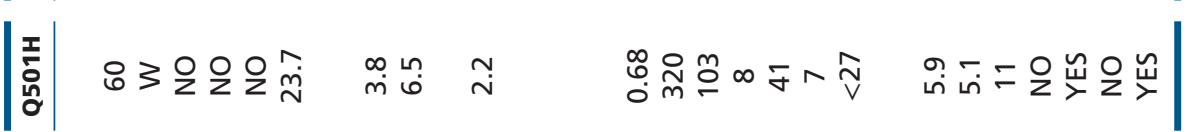

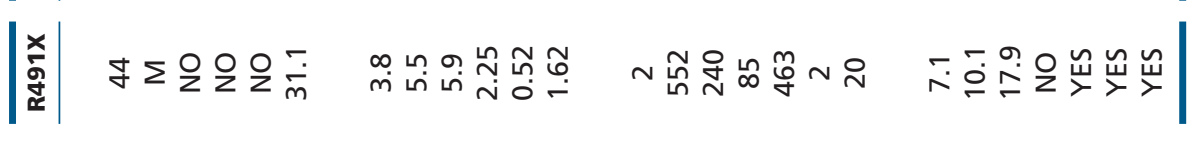

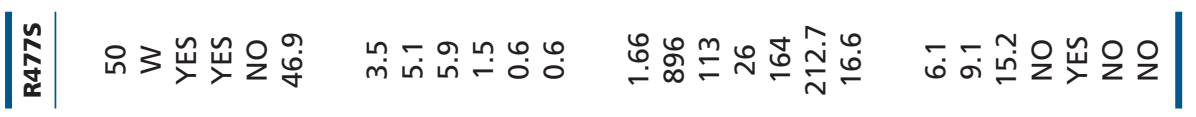

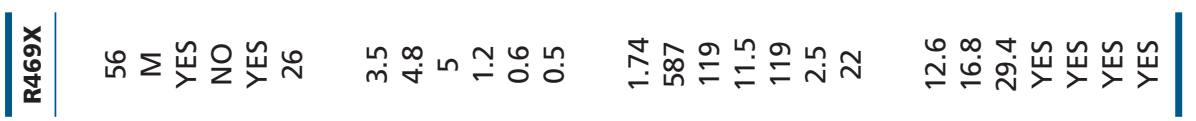

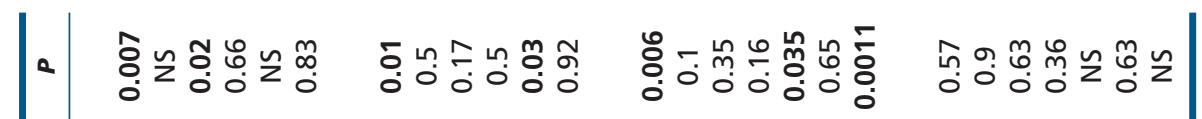

กิ

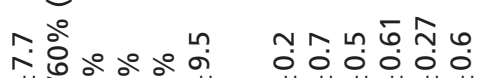

+h

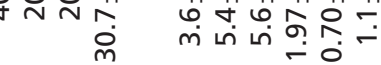

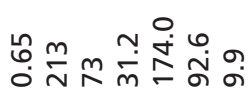

$+1+1+1+1+1+1+$

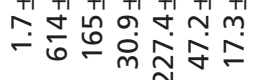

mị

$+1+1+100800$

我空

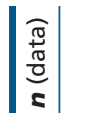

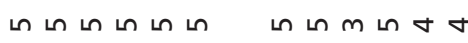

เก เก เก เก เก เก เก

เก เก เก เก เก เก เก

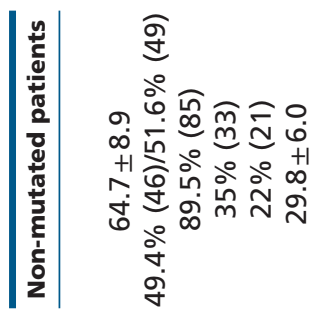

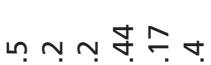
in $N$ -

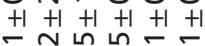

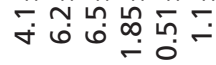

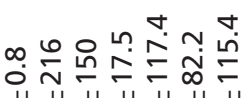

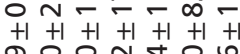

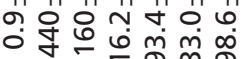

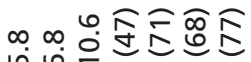
$1+1$
+1 n 60 o 음 向的穴六市

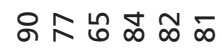

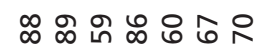

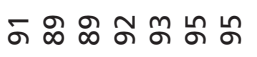




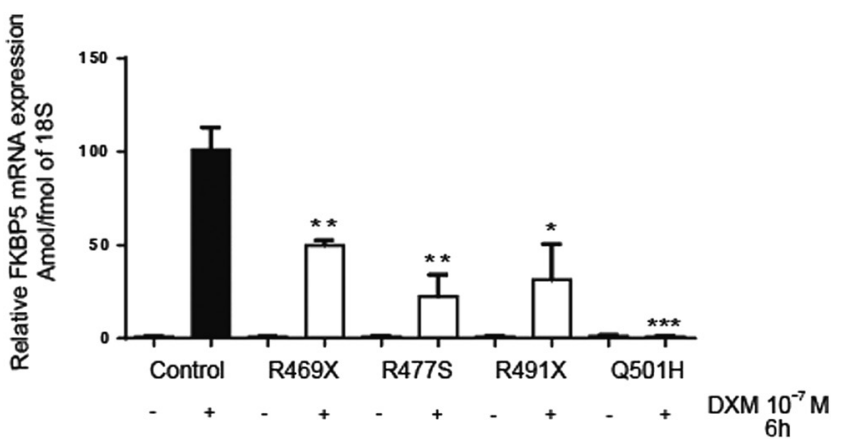

Figure 4

GR haploinsufficiency in mutated patients' fibroblasts. Ex vivo characterization of GR mutations in patients' fibroblasts. Patient with L672P mutation was lost of follow-up. FKBP5 is a GR target gene. After 6-h exposure of vehicle or $10^{-7} \mathrm{M} D X M$, FKBP5 mRNA expression was measured by RT-qPCR in fibroblasts and normalized with rRNA 18S. The DXM induction of FKBP5 mRNA in patient's fibroblasts with wild-type GR (Control) was arbitrarily set at $100 \%$. Results are mean \pm S.E.M. of two independent determinations performed in duplicate. ${ }^{*} P<0.05, * * P<0.01, * * * P<0.005$ was statistically significant with non-parametric Mann-Whitney $U$ tests.

\section{GR polymorphisms}

We also evaluated some common GR polymorphisms frequently described in the general population, notably ER22/23EK (rs6189 and rs6190, with minor allele frequency of $1.8 \%$ and $1.8 \%$, respectively), rs10482622 (0.8\% in the general population), N363S (rs6195, 2.1\%), all located in the exon 2 and BclI (rs41423247, 25.5\%), located in the intron 2, rs6188 located in the intron 4 and pN766N (rs6196) located in the $9 \alpha$ exon (26.4\% and $13.0 \%$, respectively) (Fig. 5). Minor allelic frequencies of rs6189 and rs6190 (ER22/23EK), rs10482622, N363S, rs6188 and pN766N were calculated at 1.98, 1.98, 0.50, 0.50, 22.8 and 14.8, respectively, in the patients included in Muta-GR study (Table 3), without any difference with the general population as estimated by the exome aggregation consortium (ExaC: https:// www.exac.broadinstitute.org/ and 1000 genomes: http:// www.internationalgenome.org/). Only BclI polymorphism (rs41423247) was over-represented in this cohort $(38.7 \%$ vs $25.5 \%$ in the general population, $P=0.0045)$. Only one mutated patient had a heterozygous polymorphism rs6188.

\section{Selected criteria to search for NR3C1 mutations in eligible patients}

In order to select patients with bilateral adrenal hyperplasia suitable for GR molecular investigation,

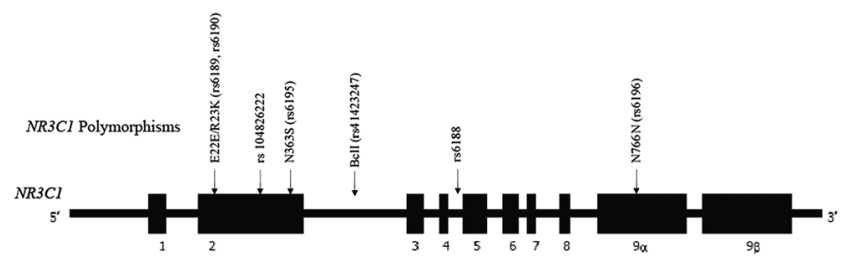

Figure 5

GR polymorphisms of 100 included patients. Localization of GR polymorphisms: ER22/23EK (rs6189, rs6190), rs10482622, N363S (rs6195) located in the exon 2, Bcll (rs41423247) located in the intron 2, rs6188 located in the intron 4, N766N (rs6196) located in the exon $9 \alpha$.

we searched for the common clinical and/or biological features of mutated patients. Clinically, as expected, none of them had any Cushing's syndrome signs. Four out of 5 mutated patients had only mild glucocorticoid resistance syndrome. However, all mutated patients presented with kalemia $<4.0 \mathrm{mmol} / \mathrm{L}$ contrasting with plasma aldosterone levels below the lower limit of normal values. Finally, as depicted in Fig. 6, among 100 included patients in the Muta-GR study, the initial prevalence of GR mutations evaluated at 5\% (5/100 patients), increased up to $16 \%$ (5/32 patients) in those with bilateral adrenal hyperplasia AND low or normal aldosterone levels AND kalemia $<4 \mathrm{mmol} / \mathrm{L}$. Of importance, the prevalence of GR mutations increased up to $44 \%$ (4/9 patients) if one takes into account the four following criteria: Bilateral adrenal hyperplasia and glucocorticoid resistance syndrome (elevated UFC or elevated 8.00 AM cortisol after $1 \mathrm{mg}$ DST) and low aldosterone levels and kalemia $<4 \mathrm{mmol} / \mathrm{L}$.

\section{Discussion}

We identify 5 heterozygous GR mutations in patients presenting with bilateral adrenal hyperplasia associated with biological hypercortisolism or hypertension without Cushing's syndrome signs among 100 included patients in the Muta-GR study. Therefore, the prevalence of NR3C1 mutations in the Muta-GR patients is 5\%. Up to date, only 26 GR loss-of-function mutations (including ours) have been reported in the literature, which leads us to believe that the prevalence of NR3C1 mutations is largely underestimated.

Historically, the first GR mutation was described in a patient with severe hypertension and hypokalemia associated with a glucocorticoid resistance syndrome characterized by high UFC and high 8-AM ACTH level, consistent with the lack of negative feedback of cortisol 
Table 3 GR polymorphisms.

\begin{tabular}{|c|c|c|c|c|c|}
\hline SNP polymorphism & Nucleotides & Protein & $\boldsymbol{n}$ (data) & ExaC or 1000 genomes & $\boldsymbol{P}$ \\
\hline rs6189 & c. $66 \mathrm{G}>\mathrm{A}$ & E22E & & & \\
\hline GG & & & 95 & & \\
\hline GA & & & 5 & & \\
\hline Carrier of allele $A$ & & & $1.98 \%$ & $1.8 \%(2216 / 126280)$ & 0.64 \\
\hline rs6190 & c. $68 \mathrm{G}>\mathrm{A}$ & $\mathrm{R} 23 \mathrm{~K}$ & & & \\
\hline GG & & & 96 & & \\
\hline GA & & & 4 & & \\
\hline Carrier of allele $A$ & & & $1.98 \%$ & $1.8 \%(2216 / 126280)$ & 0.62 \\
\hline rs10482622 & c. $879 \mathrm{G}>\mathrm{A}$ & K293K & & & \\
\hline GG & & & 99 & & \\
\hline GA & & & 1 & & \\
\hline Carrier of allele $A$ & & & $0.50 \%$ & $0.8 \%(941 / 121252)$ & 0.96 \\
\hline N363S (rs6195) & c. $1088 \mathrm{~A}>\mathrm{G}$ & N363S & & & \\
\hline AA & & & 99 & & \\
\hline AG & & & 1 & & \\
\hline Carrier of allele G & & & $0.50 \%$ & $2.1 \%(2163 / 121268)$ & 0.2 \\
\hline$B c / l(r s 41423247)$ & c. $1184+646 C>G$ & & & & \\
\hline $\mathrm{CC}$ & & & 35 & & \\
\hline CG & & & 44 & & \\
\hline GG & & & 14 & & \\
\hline Carrier of allele G & & & $38.70 \%$ & $25.5 \%(1275 / 5008)$ & 0.0045 \\
\hline rs6188 & c. $1469-16 G>T$ & & & & \\
\hline GG & & & 61 & & \\
\hline GT & & & 36 & & \\
\hline TT & & & 3 & & \\
\hline Carrier of allele $\mathrm{T}$ & & & $22.80 \%$ & $26.4 \%(31472 / 119366)$ & 0.16 \\
\hline rs6196 & c. $2298 \mathrm{~A}>\mathrm{G}$ & $\mathrm{pN} 766 \mathrm{~N}$ & & & \\
\hline AA & & & 73 & & \\
\hline$A G$ & & & 24 & & \\
\hline GG & & & 3 & & \\
\hline Carrier of allele G & & & $14.80 \%$ & $13 \%(15723 / 121026)$ & 0.56 \\
\hline
\end{tabular}

ER22/23EK polymorphism corresponds to two linked polymorphisms in codons 22 and 23 GGA.GAG to GAA.AAG leading to one amino acid change ER to EK (4). The rs 10482622 is a $\mathrm{T} \rightarrow \mathrm{C}: 12$ patients were heterozygous (TC) and 3 patients homozygous (CC) for this polymorphism. N363S is the result of a $\mathrm{A} \rightarrow \mathrm{G}$ change. One patient carries this polymorphism. Bcll polymorphism (rs41423247) is a C to G change. 38.7\% of Muta-GR patients carry this polymorphism. The rs6188 polymorphism is the result of the changing of $\mathrm{G} \rightarrow \mathrm{T}$. Thirty-six patients were heterozygous (GT) and 3 patients homozygous (TT). pN766N (rs6196) is the result of an $A \rightarrow G$ substitution: 24 patients were heterozygous (AG) and 3 were homozygous (GG).

on HPA axis $(33,34)$. Likewise, patients carrying the thirteen GR loss-of-function mutations, subsequently described up to $2010(6,7,8,10,12,13,15)$, exhibited an overt glucocorticoid resistance phenotype. Obviously, our present study underscores the large variety of clinical, biological and radiological signs that could be associated with GR mutations. One patient (Q501H mutation carrier) had only an elevated midnight plasma cortisol

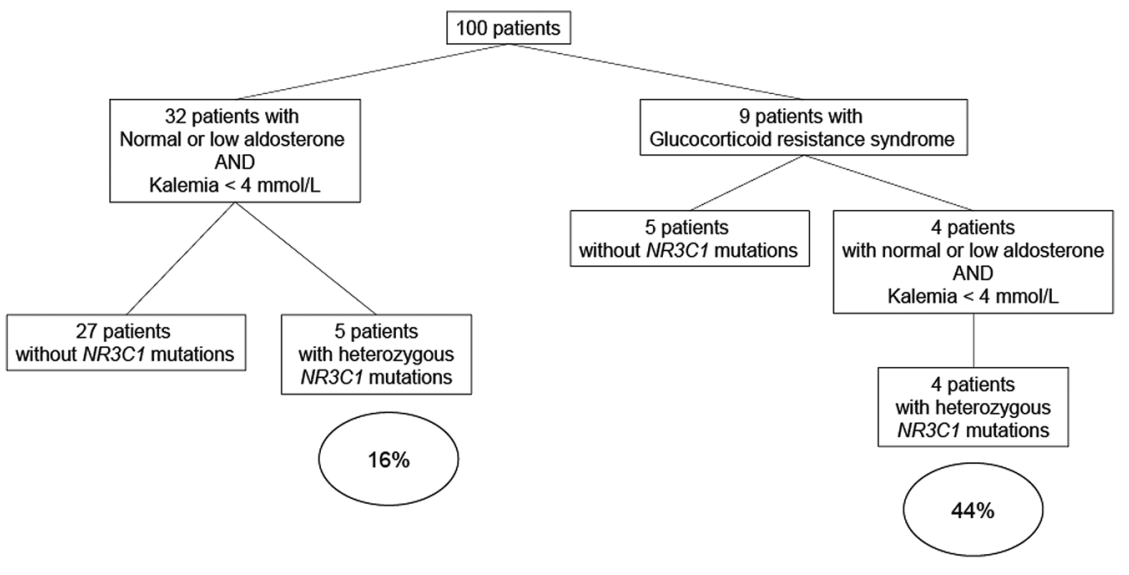

\section{Figure 6}

High prevalence of NR3C1 mutations in selected patients. Among 100 included patients, 32 patients had normal or low aldosterone levels associated with kalemia $<4 \mathrm{mmol} / \mathrm{L}$ resulting in a prevalence of $\mathrm{GR}$ mutations increased to $16 \%$. Nine patients also had glucocorticoid resistance syndrome, leading to the prevalence of GR mutations increased up to $44 \%$ in such patients. 
level but with preservation of the negative feedback loop on HPA axis. Although increased ACTH levels have been regularly reported in some cases as a direct consequence of glucocorticoid resistance, this does not seem to be the case for 4 out of 5 patients of our study since only one patient had high 8-AM ACTH level (R491X mutation carrier). However, the ACTH level values, not evaluated within the very same center, should be interpreted with an extreme caution given the unstable nature of this hormonal analyte (35) and the absence of reliable and standardized measurements (36). Altogether, our data indicate that the generalized glucocorticoid resistance syndrome seems to be relatively mild in patients harboring GR loss-of-function mutations, compared to the first cases described to date. The main differential diagnosis of mild glucocorticoid resistance could be the pseudo-Cushing syndrome, whose diagnostic relies on moderately elevated UFC (below twice the ULN) and partial failure of $1 \mathrm{mg}$ DST in obese, poorly controlled diabetic, depressed or alcoholic patients (37). Four out of five mutated patients, reported in the present study, presented with these clinical and biochemical features suggesting that NR3C1 sequencing should be performed in some atypical pseudo-Cushing patients to comfort glucocorticoid resistance.

Furthermore, all mutated patients in the Muta-GR study showed alteration in the mineralocorticoid pathway. Indeed, low aldosterone levels with normal or low renin levels with or without hypertension sharply contrast with low plasma potassium levels. The first glucocorticoid-resistant patient described in 1976 had hypertension with hypokalemia, which was interpreted as a direct consequence of increased plasma deoxycorticosterone (DOC) and corticosterone concentrations due to overstimulation of adrenal glands by ACTH hypersecretion $(33,34)$. Interestingly, DOC levels were in the normal range in the 3 patients in whom these were measured (R469X (16), R477S (27) and R491X) carrier patients. Low urinary tetrahydrocortisone (THE)/ tetrahydrocortisol (THF) ratio were found in all affected GR 469X carriers, suggesting an impairment of renal 11- $\beta$ hydroxysteroid dehydrogenase type 2 (11- $\beta$ HSD2) activity (16). Indeed, 11- $\beta$ HSD2 enzyme metabolizes cortisol into cortisone, thus preventing cortisol to bind and activate the renal mineralocorticoid receptor (MR), responsible for sodium retention, volume expansion and HBP. Few

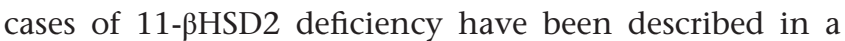
context of ectopic ACTH syndrome (38) and HSD11B2 gene mutations (39). Moreover, HSD11B2 gene seems to be a glucocorticoid-inducible target gene since human placental 11- $\beta$ HSD2 mRNA expression increased after DXM stimulation that was inhibited by GR antagonist RU486 (40), suggesting the involvement of GR in the regulation of 11- $\beta \mathrm{HSD} 2$ activity. Taken together, we propose that altered GR signaling may be responsible for a decreased $11-\beta H S D 2$ activity, leading to inefficient glucocorticoid breakdown. As a result, elevated cortisol concentrations in mutated patients could induce illicit occupation and activation of the unprotected MR which, in turn, could lead to hypokalemia despite low plasma aldosterone levels, in the context of apparent mineralocorticoid excess or pseudohypermineralocorticism.

Herein, we demonstrate GR haploinsufficiency in mutated patients and propose that it could be a potential cause of bilateral adrenal hyperplasia. Indeed, several authors already demonstrated the expression of GR in the normal adrenal gland (41) and its involvement in different pathologies such as adrenocortical carcinomas (42) or nodules of primary pigmented nodular adrenocortical disease tissues (43).

One recurrent pathophysiological mechanism evoked for bilateral adrenal hyperplasia in the context of GR lossof-function mutations was the ACTH overstimulation of the adrenal glands. This was comforted by various human and mouse studies. A single case of bilateral adrenal hyperplasia was reported in a 7-year-old boy with high ACTH level associated with heterozygous GR mutation (13). Invalidation of the $\mathrm{Nr} 3 \mathrm{cl}$ gene in mice was accompanied by an enlarged size of adrenal glands and disorganized adrenocortical cells (44). As expected, although most of $\mathrm{GR}^{-/-}$mice died $1-2 \mathrm{~h}$ postnatally, they presented with high corticosterone and ACTH levels consistent with altered HPA regulation. However, heterozygous $\mathrm{GR}^{+/-}$mice also had larger adrenal glands (17) but normal ACTH levels, precluding an exclusive role of high circulating ACTH levels in the pathogenesis of adrenal hyperplasia. In our study, the majority of mutated patients had normal ACTH levels with no hirsutism in women and no elevated plasma DOC levels, ruling out a simple ACTH overstimulation of the adrenal glands. Along this line, a positive ultrashort regulatory loop exerted by glucocorticoids via GR on steroidogenesis was reported in human adrenocortical H295R cells, independently of ACTH signaling (45). Collectively, the mechanisms by which GR haploinsufficiency may lead to bilateral adrenal hyperplasia remain to be elucidated but clearly cannot be simply restricted to a chronic ACTH overstimulation, even though we have not explored the potential role of intraadrenal endogenous ACTH release, recently reported (46).

The second objective of the Muta-GR study was to evaluate NR3C1 polymorphism frequencies associated 
with adrenal hyperplasia compared to the general population. BclI polymorphism (rs41423247) was overrepresented in the Muta-GR cohort compared to the general population, in contrast to Tzanela et al. (47), who did not detect higher frequency of bilateral masses in $\mathrm{BclI}$ carriers among 95 patients with adrenal incidentalomas. Nevertheless, despite the number of Muta-GR patients, a direct relationship between bilateral adrenal incidentaloma and minor allelic frequencies of some common GR polymorphisms (rs6189, rs6190, rs10482622, rs6195, rs41423247, rs6188 and rs6196) has not been established. This contrasts with other studies that have suggested a role of these polymorphisms in unilateral adrenal incidentaloma $(47,48)$. Altogether, except BclI, no association was found between the presence of such polymorphisms and bilateral adrenal hyperplasia in our series.

There are several limitations of this multicenter study. Indeed, MDCT examinations were performed in each independent center on different MDCT units and with various protocols of image acquisitions so that the axial section thickness was different among the centers and the measures of adrenal volume could have been slightly impacted by these differences (29). However, analysis of adrenal hyperplasia's appearance with manual measurements of adrenal limbs and bodies, as well as assessment of the presence of nodules and calculation of adrenal glands volume was centralized and performed by a single operator. Moreover, biochemical and hormonal analyses were performed in each center with inherent methodological differences and variations in normal ranges, impeding direct value comparison especially for some specific hormones as mentioned earlier. This led us to express some results such as UFC, normalized to the ULN.

Our study has direct clinical implications. Indeed, identification of NR3C1 mutation in a patient presenting with adrenal hyperplasia and alteration of cortisol secretion excludes false diagnosis of preclinical Cushing's syndrome or pseudo-Cushing's syndrome. Molecular screening could be extended to the direct family members. This has also important consequences on the follow-up and management of such patients, in whom no further invasive test should be proposed, adrenocortical surgery should be excluded while appropriate pharmacological strategies (mineralocorticoid antagonists) could be envisioned. The pathophysiological significance and the precise clinical pathogenesis of NR3C1 mutations remain to be clearly established. However, one has to take into account the presence of pseudohypermineralocorticism associated with these genetic alterations, especially with respect to its potential impact on cardiovascular system.

In conclusion, we discovered 5 original heterozygous GR mutations in a population of 100 patients with bilateral adrenal hyperplasia associated with biological hypercortisolism and/or hypertension without Cushing's syndrome signs. Most of mutated patients harbored a mild generalized glucocorticoid resistance and a pseudohypermineralocorticism. We suggest that NR3C1 genetic alterations should be systematically searched in selected patients notably those presenting with eligible criteria, as well as in pseudo-Cushing patients for the benefit of both the patients and their families.

\section{Declaration of interest}

The authors declare that there is no conflict of interest that could be perceived as prejudicing the impartiality of this study.

\section{Funding}

$\mathrm{G} V$ is the recipient of a doctoral fellowship from the Fondation pour la Recherche Médicale (FRM). This work was supported by the French Ministry of Health (Programme Hospitalier de Recherche Clinique National) (PHRC2011-N11-01) and grants from Institut National de la Santé et de la Recherche Médicale (Inserm) and Paris Sud University.

\section{Author contribution statement}

$B D$ and $M L$ contributed to the study concept and design. Investigators referred the patients. G $\mathrm{V}$ performed the analysis. C H supervised C T examination. $\mathrm{G} V$ performed statistical analysis. J B analyzed $\mathrm{G} R$ mutations and polymorphisms. G V, S T, C H, B D and M L contributed to the drafting of the paper and shared the responsibility to submit the manuscript for publication. All authors analyzed the data, corrected and approved the final version of the manuscript.

\section{Acknowledgments}

List of investigaors in the MUTA-GR study: $\mathrm{Dr} F$ Amiot-Chapoutot $(\mathrm{CH}$ Troyes, France); Dr D Ancelle (CH St Lô, France); Dr F Bertoin (CHU Reims, France); Prof. T Brue (CHU Marseille, France); Prof. P Caron (CHU Toulouse, France); Prof. F Borson-Chazot (HCL, Lyon, France); Prof. S Christin-Maitre (CHU St Antoine, Paris, France); Prof. O Chabre (CHU Grenoble, France); Prof. R Dessailloud (CHU Amiens, France); Prof. B Estour (CHU SaintEtienne, France); Dr H Grulet (CHU Reims, France); Dr F Illouz (CHU Angers, France); Prof. N Jeandidier (CHU Strasbourg, France); Prof. V Kerlan (CHU Brest, France); Prof. M Klein (CHU Nancy, France); Prof. A Penfornis (CHU Besançon, France); Dr P Pierre (CHU Tours, France); Prof. A Tabarin (CHU Bordeaux, Pessac, France); Prof. P Touraine (CHU Pitié-Salpetrière, Paris, France); Prof. M C Vantyghem (CHRU Lille, France); Prof. J Young (CHU Bicêtre, Le Kremlin Bicêtre, France).

The authors would like to thank Dr Coralie Barbe and Edith Kassa (CHU Reims) who helped us to manage the Muta-GR study. They thank Isabelle Boucly (CHU Bicêtre) for excellent technical assistance in GR mutation screening and Neila Belassaoui (CHU Bicêtre) for GR polymorphism determination. They also are indebted to $\mathrm{Dr}$ Alexandre Buffet (CHU Toulouse) for providing us with the skin biopsy of one patient and Dr Eric Pussard (CHU Bicêtre) for LCMSMS measurements of steroidomic profiling in one patient. $\mathrm{G} \mathrm{V}$ is the recipient of a doctoral fellowship from the 'Fondation pour la Recherche Médicale' (FRM). 


\section{References}

1 Gross KL \& Cidlowski JA. Tissue-specific glucocorticoid action: a family affair. Trends in Endocrinology and Metabolism 200819 331-339. (https://doi.org/10.1016/j.tem.2008.07.009)

2 Bamberger CM, Bamberger AM, de Castro M \& Chrousos GP. Glucocorticoid receptor beta, a potential endogenous inhibitor of glucocorticoid action in humans. Journal of Clinical Investigation 1995 95 2435-2441. (https://doi.org/10.1172/JCI117943)

3 Koper JW, van Rossum EFC \& van den Akker ELT. Glucocorticoid receptor polymorphisms and haplotypes and their expression in health and disease. Steroids 201492 62-73. (https://doi. org/10.1016/j.steroids.2014.07.015)

4 Russcher H, Smit P, van den Akker ELT, van Rossum EFC, Brinkmann AO, de Jong FH, Lamberts SWJ \& Koper JW. Two polymorphisms in the glucocorticoid receptor gene directly affect glucocorticoid-regulated gene expression. Journal of Clinical Endocrinology and Metabolism 200590 5804-5810. (https://doi. org/10.1210/jc.2005-0646)

5 Karl M, Lamberts SW, Koper JW, Katz DA, Huizenga NE, Kino T, Haddad BR, Hughes MR \& Chrousos GP. Cushing's disease preceded by generalized glucocorticoid resistance: clinical consequences of a novel, dominant-negative glucocorticoid receptor mutation. Proceedings of the Association of American Physicians $1996 \mathbf{1 0 8}$ 296-307.

6 Ruiz M, Lind U, Gåfvels M, Eggertsen G, Carlstedt-Duke J, Nilsson L, Holtmann M, Stierna P, Wikström AC \& Werner S. Characterization of two novel mutations in the glucocorticoid receptor gene in patients with primary cortisol resistance. Clinical Endocrinology 2001 55 363-371. (https://doi.org/10.1046/j.1365-2265.2001.01323.x)

7 Karl M, Lamberts SW, Detera-Wadleigh SD, Encio IJ, Stratakis CA, Hurley DM, Accili D \& Chrousos GP. Familial glucocorticoid resistance caused by a splice site deletion in the human glucocorticoid receptor gene. Journal of Clinical Endocrinology and Metabolism 199376 683-689. (https://doi.org/10.1210/ jcem.76.3.8445027)

8 Mendonca BB, Leite MV, de Castro M, Kino T, Elias LLK, Bachega TAS, Arnhold IJP, Chrousos GP, \& Latronico AC. Female pseudohermaphroditism caused by a novel homozygous missense mutation of the GR gene. Journal of Clinical Endocrinology and Metabolism 200287 1805-1809. (https://doi.org/10.1210/ jcem.87.4.8379)

9 Trebble P, Matthews L, Blaikley J, Wayte AWO, Black GCM, Wilton A \& Ray DW. Familial glucocorticoid resistance caused by a novel frameshift glucocorticoid receptor mutation. Journal of Clinical Endocrinology and Metabolism 201095 E490-E499. (https://doi. org/10.1210/jc.2010-0705)

10 Hurley DM, Accili D, Stratakis CA, Karl M, Vamvakopoulos N, Rorer E, Constantine K, Taylor SI \& Chrousos GP. Point mutation causing a single amino acid substitution in the hormone binding domain of the glucocorticoid receptor in familial glucocorticoid resistance. Journal of Clinical Investigation 199187 680-686. (https:// doi.org/10.1172/JCI115046)

11 Nader N, Bachrach BE, Hurt DE, Gajula S, Pittman A, Lescher R $\&$ Kino T. A novel point mutation in helix 10 of the human glucocorticoid receptor causes generalized glucocorticoid resistance by disrupting the structure of the ligand-binding domain. Journal of Clinical Endocrinology and Metabolism 201095 2281-2285. (https:// doi.org/10.1210/jc.2009-2463)

12 Charmandari E, Raji A, Kino T, Ichijo T, Tiulpakov A, Zachman K $\&$ Chrousos GP. A novel point mutation in the ligand-binding domain (LBD) of the human glucocorticoid receptor (hGR) causing generalized glucocorticoid resistance: the importance of the $\mathrm{C}$ terminus of hGR LBD in conferring transactivational activity. Journal of Clinical Endocrinology and Metabolism 200590 3696-3705. (https:// doi.org/10.1210/jc.2004-1920)
13 Charmandari E, Kino T, Ichijo T, Jubiz W, Mejia L, Zachman K \& Chrousos GP. A novel point mutation in helix 11 of the ligand-binding domain of the human glucocorticoid receptor gene causing generalized glucocorticoid resistance. Journal of Clinical Endocrinology and Metabolism 200792 3986-3990. (https://doi.org/10.1210/jc.2006-2830)

14 Vottero A, Kino T, Combe H, Lecomte P \& Chrousos GP. A novel, C-terminal dominant negative mutation of the GR causes familial glucocorticoid resistance through abnormal interactions with p160 steroid receptor coactivators. Journal of Clinical Endocrinology and Metabolism 200287 2658-2667. (https://doi.org/10.1210/ jcem.87.6.8520)

15 McMahon SK, Pretorius CJ, Ungerer JPJ, Salmon NJ, Conwell LS, Pearen MA \& Batch JA. Neonatal complete generalized glucocorticoid resistance and growth hormone deficiency caused by a novel homozygous mutation in Helix 12 of the ligand binding domain of the glucocorticoid receptor gene (NR3C1). Journal of Clinical Endocrinology and Metabolism 201095 297-302. (https://doi. org/10.1210/jc.2009-1003)

16 Bouligand J, Delemer B, Hecart AC, Meduri G, Viengchareun S, Amazit L, Trabado S, Fève B, Guiochon-Mantel A, Young J et al. Familial glucocorticoid receptor haploinsufficiency by nonsense mediated mRNA decay, adrenal hyperplasia and apparent mineralocorticoid excess. PLoS ONE 20105 e13563. (https://doi. org/10.1371/journal.pone.0013563)

17 Michailidou Z, Carter RN, Marshall E, Sutherland HG, Brownstein DG, Owen E, Cockett K, Kelly V, Ramage L, Al-Dujaili ES et al. Glucocorticoid receptor haploinsufficiency causes hypertension and attenuates hypothalamic-pituitary-adrenal axis and blood pressure adaptions to high-fat diet. FASEB Journal 200822 3896-3907. (https://doi.org/10.1096/fj.08-111914)

18 Barzon L, Scaroni C, Sonino N, Fallo F, Gregianin M, Macrì C \& Boscaro M. Incidentally discovered adrenal tumors: endocrine and scintigraphic correlates. Journal of Clinical Endocrinology and Metabolism 199883 55-62. (https://doi.org/10.1210/jcem.83.1.4501)

19 Kastelan D, Kraljevic I, Dusek T, Knezevic N, Solak M, Gardijan B, Kralik M, Poljicanin T, Skoric-Polovina T \& Kastelan Z. The clinical course of patients with adrenal incidentaloma: is it time to reconsider the current recommendations? European Journal of Endocrinology 2015 173 275-282. (https://doi.org/10.1530/EJE-15-0199)

20 Paschou SA, Kandaraki E, Dimitropoulou F, Goulis DG \& Vryonidou A. Subclinical Cushing's syndrome in patients with bilateral compared to unilateral adrenal incidentalomas: a systematic review and meta-analysis. Endocrine 201651 225-235. (https://doi. org/10.1007/s12020-015-0776-6)

21 Lacroix A, Ndiaye N, Tremblay J \& Hamet P. Ectopic and abnormal hormone receptors in adrenal Cushing's syndrome. Endocrine Reviews 200122 75-110. (https://doi.org/10.1210/edrv.22.1.0420)

22 Zennaro MC, Fernandes-Rosa F, Boulkroun S \& Jeunemaitre X.Bilateral idiopathic adrenal hyperplasia: genetics and beyond. Hormone and Metabolic Research 201547 947-952. (https:// doi.org/10.1055/s-0035-1565198)

23 Assié G, Libé R, Espiard S, Rizk-Rabin M, Guimier A, Luscap W, Barreau O, Lefèvre L, Sibony M, Guignat L et al. ARMC5 mutations in macronodular adrenal hyperplasia with Cushing's syndrome. New England Journal of Medicine 2013369 2105-2114. (https://doi. org/10.1056/NEJMoa1304603)

24 Emms H, Tsirou I, Cranston T, Tsagarakis S \& Grossman AB. Do patients with incidentally discovered bilateral adrenal nodules represent an early form of ARMC5-mediated bilateral macronodular hyperplasia? Endocrine 201653 801-808. (https://doi.org/10.1007/ s12020-016-0988-4)

25 Hong AR, Kim JH, Park KS, Kim KY, Lee JH, Kong SH, Lee SY, Shin CS, Kim SW \& Kim SY. Optimal follow-up strategies for adrenal incidentalomas: Reappraisal of the 2016 ESE-ENSAT guidelines in real clinical practice. European Journal of Endocrinology 2017177 475-483. (https://doi.org/10.1530/EJE-17-0372) 
26 Fassnacht M, Arlt W, Bancos I, Dralle H, Newell-Price J, Sahdev A, Tabarin A, Terzolo M, Tsagarakis S \& Dekkers OM. Management of adrenal incidentalomas: European Society of Endocrinology Clinical Practice Guideline in collaboration with the European Network for the Study of Adrenal Tumors. European Journal of Endocrinology 2016 175 G1-G34. (https://doi.org/10.1530/EJE-16-0467)

27 Vitellius G, Fagart J, Delemer B, Amazit L, Ramos N, Bouligand J, Le Billan F, Castinetti F, Guiochon-Mantel A, Trabado S et al. Three novel heterozygous point mutations of NR3C1 causing glucocorticoid resistance. Human Mutation 201637 794-803. (https://doi.org/10.1002/humu.23008)

28 Lingam RK, Sohaib SA, Vlahos I, Rockall AG, Isidori AM, Monson JP, Grossman A \& Reznek RH. CT of primary hyperaldosteronism (Conn's syndrome): the value of measuring the adrenal gland. American Journal of Roentgenology 2003181 843-849. (https://doi. org/10.2214/ajr.181.3.1810843)

29 Carsin-Vu A, Oubaya N, Mulé S, Janvier A, Delemer B, Soyer P \& Hoeffel C. MDCT linear and volumetric analysis of adrenal glands: normative data and multiparametric assessment. European Radiology 201626 2494-2501. (https://doi.org/10.1007/s00330-015-4063-y)

30 Newell-Price J, Bertagna X, Grossman AB \& Nieman LK. Cushing's syndrome. Lancet 2006367 1605-1617. (https://doi.org/10.1016/ S0140-6736(06)68699-6)

31 Vincent JM, Morrison ID, Armstrong P \& Reznek RH. The size of normal adrenal glands on computed tomography. Clinical Radiology 199449 453-455. (https://doi.org/10.1016/S0009-9260(05)81739-8)

32 Le Billan F, Khan JA, Lamribet K, Viengchareun S, Bouligand J, Fagart J \& Lombès M. Cistrome of the aldosterone-activated mineralocorticoid receptor in human renal cells. FASEB Journal 2015 29 3977-3989. (https://doi.org/10.1096/fj.15-274266)

33 Vingerhoeds AC, Thijssen JH \& Schwarz F. Spontaneous hypercortisolism without Cushing's syndrome. Journal of Clinical Endocrinology and Metabolism 197643 1128-1133. (https://doi. org/10.1210/jcem-43-5-1128)

34 Chrousos GP, Vingerhoeds A, Brandon D, Eil C, Pugeat M, DeVroede M, Loriaux DL \& Lipsett MB. Primary cortisol resistance in man. A glucocorticoid receptor-mediated disease. Journal of Clinical Investigation 198269 1261-1269. (https://doi.org/10.1172/ JCI110565)

35 Evans MJ, Livesey JH, Ellis MJ \& Yandle TG. Effect of anticoagulants and storage temperatures on stability of plasma and serum hormones. Clinical Biochemistry 200134 107-112. (https://doi. org/10.1016/S0009-9120(01)00196-5)

36 Pecori Giraldi F, Saccani A, Cavagnini F \& Study Group on the Hypothalamo-Pituitary-Adrenal Axis of the Italian Society of Endocrinology. Assessment of ACTH assay variability: a multicenter study. European Journal of Endocrinology 2011 164 505-512. (https:// doi.org/10.1530/EJE-10-0962)

37 Findling JW \& Raff H. Diagnosis of endocrine disease: differentiation of pathologic/neoplastic hypercortisolism (Cushing's syndrome) from physiologic/non-neoplastic hypercortisolism (formerly known as pseudo-Cushing's syndrome). European Journal of Endocrinology 2017 176 R205-R216. (https://doi.org/10.1530/EJE-16-0946)

38 Stewart PM, Walker BR, Holder G, O’Halloran D \& Shackleton CH. 11beta-Hydroxysteroid dehydrogenase activity in Cushing's syndrome: explaining the mineralocorticoid excess state of the ectopic adrenocorticotropin syndrome. Journal of Clinical Endocrinology and Metabolism 199580 3617-3620. (https://doi. org/10.1210/jcem.80.12.8530609)
39 Morineau G, Sulmont V, Salomon R, Fiquet-Kempf B, Jeunemaître X, Nicod J \& Ferrari P. Apparent mineralocorticoid excess: report of six new cases and extensive personal experience. Journal of the American Society of Nephrology 200617 3176-3184. (https://doi.org/10.1681/ ASN.2006060570)

40 van Beek JP, Guan H, Julan L \& Yang K. Glucocorticoids stimulate the expression of 11 beta-hydroxysteroid dehydrogenase type 2 in cultured human placental trophoblast cells. Journal of Clinical Endocrinology and Metabolism 200489 5614-5621. (https://doi. org/10.1210/jc.2004-0113)

41 Paust HJ, Loeper S, Else T, Bamberger AM, Papadopoulos G, Pankoke D, Saeger W \& Bamberger CM. Expression of the glucocorticoid receptor in the human adrenal cortex. Experimental and Clinical Endocrinology and Diabetes 2006114 6-10. (https://doi. org/10.1055/s-2005-873007)

42 Tacon LJ, Soon PS, Gill AJ, Chou AS, Clarkson A, Botling J, Stalberg PLH, Skogseid BM, Robinson BG, Sidhu SB et al. The glucocorticoid receptor is overexpressed in malignant adrenocortical tumors. Journal of Clinical Endocrinology and Metabolism 200994 4591-4599. (https://doi.org/10.1210/jc.2009-0546)

43 Bourdeau I, Lacroix A, Schürch W, Caron P, Antakly T \& Stratakis CA. Primary pigmented nodular adrenocortical disease: paradoxical responses of cortisol secretion to dexamethasone occur in vitro and are associated with increased expression of the glucocorticoid receptor. Journal of Clinical Endocrinology and Metabolism $2003 \mathbf{8 8}$ 3931-3937. (https://doi.org/10.1210/jc.2002-022001)

44 Cole TJ, Blendy JA, Monaghan AP, Krieglstein K, Schmid W, Aguzzi A, Fantuzzi G, Hummler E, Unsicker K \& Schütz G. Targeted disruption of the glucocorticoid receptor gene blocks adrenergic chromaffin cell development and severely retards lung maturation. Genes and Development 19959 1608-1621.

45 Asser L, Hescot S, Viengchareun S, Delemer B, Trabado S \& Lombès M. Autocrine positive regulatory feedback of glucocorticoid secretion: glucocorticoid receptor directly impacts H295R human adrenocortical cell function. Molecular and Cellular Endocrinology 2014 395 1-9. (https://doi.org/10.1016/j.mce.2014.07.012)

46 Louiset E, Duparc C, Young J, Renouf S, Tetsi Nomigni M, Boutelet I, Libé R, Bram Z, Groussin L, Caron P et al. Intraadrenal corticotropin in bilateral macronodular adrenal hyperplasia. New England Journal of Medicine 2013369 2115-2125. (https://doi.org/10.1056/ NEJMoa1215245)

47 Tzanela M, Mantzou E, Saltiki K, Tampourlou M, Kalogeris N, Hadjidakis D, Tsagarakis S \& Alevizaki M. Clinical and biochemical impact of BCL1 polymorphic genotype of the glucocorticoid receptor gene in patients with adrenal incidentalomas. Journal of Endocrinological Investigation 201235 395-400. (https://doi. org/10.3275/7840)

48 Damjanovic SS, Antic JA, Ilic BB, Cokic BB, Ivovic M, Ognjanovic SI, Isailovic TV, Popovic BM, Bozic IB, Tatic S et al. Glucocorticoid receptor and molecular chaperones in the pathogenesis of adrenal incidentalomas: potential role of reduced sensitivity to glucocorticoids. Molecular Medicine 201218 1456-1465. (https://doi. org/10.2119/molmed.2012.00261)

49 Majnik J, Patocs A, Balogh K, Toth M, Gergics P, Szappanos A, Mondok A, Borgulya G, Panczel P, Prohaszka Z et al. Overrepresentation of the N363S variant of the glucocorticoid receptor gene in patients with bilateral adrenal incidentalomas. Journal of Clinical Endocrinology and Metabolism 200691 2796-2799. (https://doi.org/10.1210/jc.2006-0066)

Received 26 December 2017

Revised version received 9 February 2018

Accepted 14 February 2018 